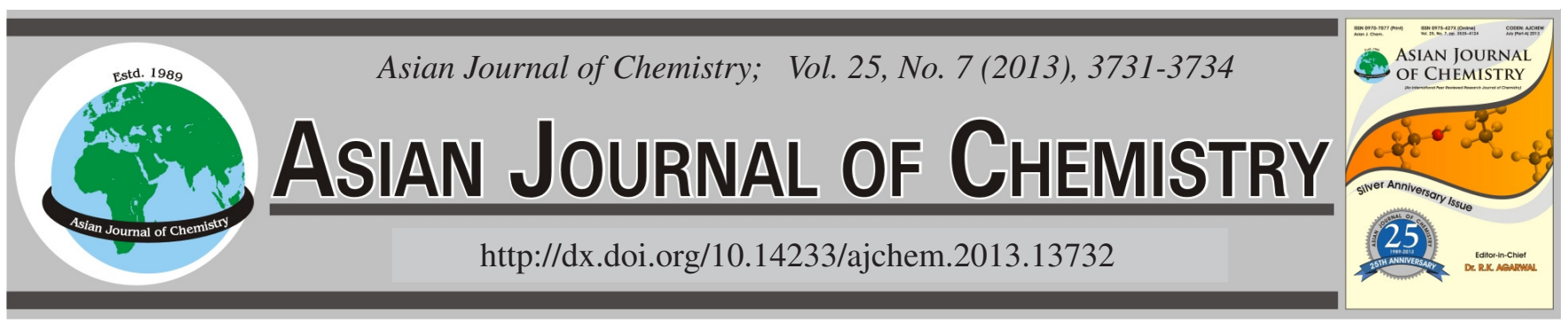

\title{
Solid Phase Extraction of Three Organic Acids from Salicornia herbacea L. Using Amino Imidazolium Ionic Liquid-Based Cartridge
}

\author{
T. Zhu, C.H. Yoon and K.H. Row*
}

Department of Chemical Engineering, Inha University, 253 Yonghyun-Dong, Nam-Ku, Incheon 402-751, South Korea

*Corresponding author: Fax: +82 32 8724046; Tel: +82 32 8607470; E-mail: rowkho@inha.ac.kr

\begin{abstract}
An amino imidazolium ionic liquid-based cartridge was prepared and developed for the selective extraction and determination of proto- I catechuic acid, caffeic acid and ferulic acid from Salicornia herbacea L. The optimum extraction condition was obtained, extraction solvent of methanol, extraction time of $1 \mathrm{~h}$ and ultrasonic power of $75 \mathrm{~W}$. High performance liquid chromatography analysis was occurred on a $\mathrm{C}_{18}$ column with ultraviolet detection at $270 \mathrm{~nm}$ and the mobile phase was acetonitrile $/ \mathrm{H}_{2} \mathrm{O} / \mathrm{CH}_{3} \mathrm{COOH}(15 / 85 / 0.05$, v/v/v, $\mathrm{pH} 5.0)$ with flow rate of $0.8 \mathrm{~mL} \mathrm{~min}^{-1}$, which showed good linearity for concentrations from $0.10-100 \mu \mathrm{g} \mathrm{mL}^{-1}$.

Key Words: Salicornia herbacea L., Extraction, Purification, Organic acids, Ionic liquids.
\end{abstract}

\section{INTRODUCTION}

Salicornia herbacea L. (S. herbacea) is a salt marsh plant of Chenopodiaceae and is commonly found in coastal Korea, China and Japan ${ }^{1}$. It has been prescribed in traditional medicines for the treatment of intestinal ailments, hepatitis, hyperlipidemia and diabetes ${ }^{2}$. Protocatechuic acid, caffeic acid and ferulic acid (Fig. 1) are naturally occurring antioxidant organic compounds in $S$. herbacea, which have been shown to act as carcinogenic inhibitors, affecting on cancer cells both in vitro and in vivo studies ${ }^{3-6}$. At present, organic solvents are mostly used in the process of extraction of targets from natural plant and it is necessary to require a solid-phase extraction process to remove impurities for the organic solvent extracts.

Solid-phase extraction has been developed for the separation, purification and solvent exchange of solutes from solutions ${ }^{7,8}$. It is a viable alternative to conventional sample preparation methods and has been used to isolate natural plant extracts $^{9}$. In our previous study ${ }^{10}$, a monolithic molecularimprinting polymer (MIP) material was prepared in situ using caffeic acid as template and method was established for the simultaneous extraction and determination of the above three organic acids from $S$. herbacea using such molecular-imprinting polymer monolithic cartridges. In order to expand research of functional stationary phase materials on extraction materials, ionic liquids (ILs) were used for modify the surface of materials ${ }^{11,12}$.

Ionic liquids has many applications, such as powerful solvents and electrically conducting fluids. Their ionic bonds<smiles>O=C(O)c1ccc(O)c(O)c1</smiles>

(a)<smiles>COc1cc(/C=C/C(=O)O)ccc1O</smiles>

(c)

Fig. 1. Chemical structures of protocatechuic acid (a), caffeic acid (b) and ferulic acid (c)

are usually stronger than the van der Waals forces between the molecules of ordinary liquids. Compare with conventional organic solvents ${ }^{7,13,14}$, ionic liquids pollute less and have improved selectivity and extraction yields of bioactive compounds from natural plants. Extraction process of caffeic acid and ferulic acid were investigated using ionic liquids as extraction solvents by Yu et al. ${ }^{15}$ and high extraction efficiency and recovery of targets were obtained. 
In this work, an ionic liquids-based cartridge was prepared and used to establish an off-line solid-phase extraction method for the simultaneous analysis of protocatechuic acid, caffeic acid and ferulic acid from $S$. herbacea.

\section{EXPERIMENTAL}

S. herbacea powders were bought from local market (Incheon, Korea). Protocatechuic acid, ferulic acid, imidazole (99\%) and 3-bromopropylamine hydrobromide (98\%) were obtained from Aldrich (Milwaukee, WI, USA). 4-(Chloromethyl) styrene $(90 \%)$, divinylbenzene $(50 \%)$ and polyvinylpyrrolidone were purchased from Tokyo Chemical Industry Co., Ltd. (Tokyo, Japan). Caffeic acid (99\%), methacrylic acid, triethylamine $(99.5 \%)$ was bought from Sigma (St Louis, MO, USA). Ethylene glycol dimethacrylate (EGDMA) was purchased from Fluka (Buchs, Switzerland). Dodecanol was purchased from Acros organics (New Jersey, USA). Cyclohexanol and 2,2'-azobis(isobutyronitrile) (AIBN) were purchased from Junsei Chemical Co. Ltd. (Japan) and refined before use. Methanol $(\mathrm{MeOH})$, ethanol and chloroform were obtained from Duksan Pure Chemical Co., Ltd. (Ansan, Korea). All other reagents used in the experiment were HPLC or analytical grade. Double distilled water was filtered with a vacuum pump (Division of Millipore, Waters, USA) and filter (HA-0.45, Division of Millipore, Waters, USA) before use. All the samples were filtered (MFS-25, 0.2 $\mu \mathrm{m}$ TF, Whatman, USA) before injection into the HPLC system.

The chromatography system comprised a Waters 600s Multi solvent Delivery System, a Waters 616 liquid chromatography (Waters Associates, Milford, MA, USA), a Rheodyne injector ( $20 \mu \mathrm{L}$ sample loop) and a variable wavelength 2487 UV dual channel detector. Autochro-2000 software (Younglin Co. Ltd., Korea) was used for data acquisition. Analyses were performed on an OptimaPak $\mathrm{C}_{18}$ column $(5 \mathrm{~mm}, 150 \mathrm{~mm} \times$ $4.6 \mathrm{~mm}$, i.d., RS tech Corporation, Daejeon, Korea) with a guard column $\left(10 \mathrm{~mm} \times 4.6 \mathrm{~mm}\right.$, i.d.) packed with $\mathrm{C}_{18}$ materials. All glassware was washed with deionized water and acetone and dried at room temperature.

Preparation of ionic liquids-based cartridge: Aminoimidazolium ionic liquids-based cartridge was synthesized as follows: $0.2 \mathrm{~g}$ polyvinylpyrrolidone was dissolved in $55 \mathrm{~mL}$ of ethanol/water (10:1, v/v) in a two-neck flask. A mixture of 4-(chloromethyl)styrene $(5.0 \mathrm{~g})$, divinylbenzene $(0.5 \mathrm{~g})$ and $2,2^{\prime}$-azobis(isobutyronitrile) ( $0.15 \mathrm{~g}$ ) was added under nitrogen and rapid stirring. The resulting emulsion was heated to $73^{\circ} \mathrm{C}$ for $12 \mathrm{~h}$ for polymerization. The obtained dried polymer ( $\mathrm{PSCl})$ was reacted with imidazole using triethylamine as catalyst and was placed in a reaction flask containing toluene and triethylamine. The suspension was stirred for $0.5 \mathrm{~h}$, with imidazole then gradually added over $10 \mathrm{~min}$ with stirring. After refluxing for $12 \mathrm{~h}$, the reaction was stopped and washed. The polymer bonded with imidazole (PSIm) was dried and placed in a flask with ethanol and 3-bromopropylamine hydrobromide ${ }^{16}$. The suspension was then refluxed with stirring for $24 \mathrm{~h}$. After washing with ethanol and drying at $70{ }^{\circ} \mathrm{C}$, the amino imidazolium polymer (PSImN) was obtained ${ }^{17}$. This polymer was ground into powder and was packed tight into a cartridge (15 $\mathrm{mm} \times 9.0 \mathrm{~mm}$, i.d.).
Sample preparation and chromatography: Stock standard solutions of organic acids were prepared at $1,000 \mu \mathrm{g}$ $\mathrm{mL}^{-1}$. To investigate this method, a series of mixed standard solutions containing three acids were prepared at five different concentrations from $0.10-100.0 \mu \mathrm{g} \mathrm{mL}^{-1}$ using these stock standard solutions. HPLC separation was performed on a $\mathrm{C}_{18}$ column at room temperature using an acetonitrile/ $\mathrm{H}_{2} \mathrm{O} /$ acetic acid (15/85/0.05, v/v/v, pH 5.0) mobile phase at a flow rate of $0.8 \mathrm{~mL} \mathrm{~min}^{-1}$ with detection carried out at $270 \mathrm{~nm}$. Distilled water was filtered with a vacuum pump and filter (HA-0.45 $\mu \mathrm{m}$; Millipore, Waters, USA) before use.

Extraction of S. herbacea: In a typical procedure, $2 \mathrm{~g}$ of $S$. herbacea powder was dissolved in $40 \mathrm{~mL}$ four different solvents (chloroform, ethanol, methanol and water) and ultrasonic-assisted extraction (UAE) of organic acids were carried out at room temperature for 20, 40, 60, 80 and $100 \mathrm{~min}$, respectively. After stirring, the extracts were sonicated and filtered. Then, the extracts were concentrated to a volume of $10 \mathrm{~mL}$ using a rotary evaporator. Finally, $0.5 \mathrm{~mL}$ of extracts solutions were loaded into the solid-phase extraction cartridge and washed with $5 \mathrm{~mL}$ acetonitrile/water (10:90, v/v) was used as eluant to remove the interferents. Finally, the extracts were eluted with $5 \mathrm{~mL}$ of acetonitrile/water (90:10, v/v) and the filtrates were evaporated to dryness and reconstituted in $0.5 \mathrm{~mL}$ mobile phase for further HPLC analysis. The solid-phase extraction cartridge was washed again with acetonitrile for the next use.

\section{RESULTS AND DISCUSSION}

Optimization of extraction process: In order to get higher extraction yields of three organic acids, four extraction solvents (chloroform, ethanol, methanol and water) were investigated. During this analysis, $40.0 \mathrm{~mL}$ of the solvent was used to extract $2 \mathrm{~g}$. herbacea powder for $1 \mathrm{~h}$. Ultrasonication can greatly reduce the required time and the ultrasonic power was set at $75 \mathrm{~W}$. Comparing the extracted amounts of three organic acids in the different solvents, methanol was proved to be the best solvent. Therefore, methanol was selected for the following experiments (Fig. 2).

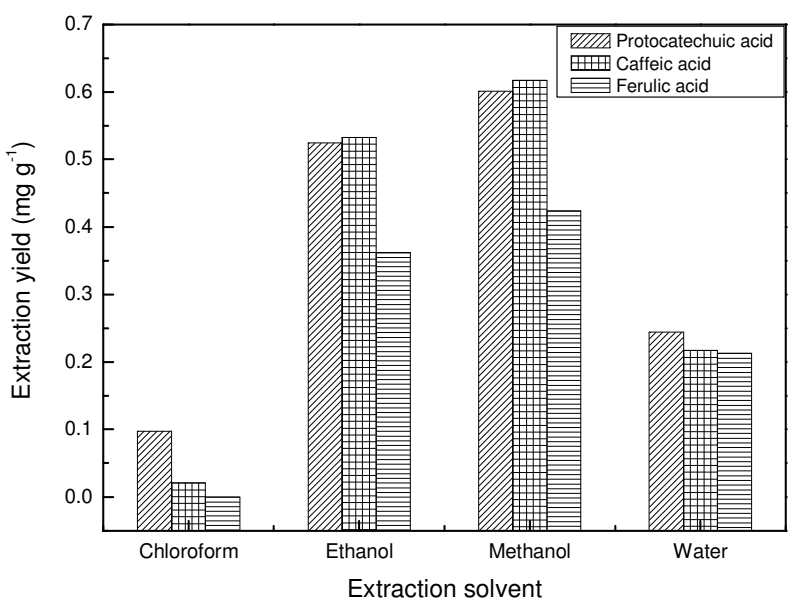

Fig. 2. Effects of different extraction solvents on the extraction yields of protocatechuic acid, caffeic acid and ferulic acid

Different extraction times (20, 40, 60, 80 and $100 \mathrm{~min})$ were tested, when ultrasonic power was set at $75 \mathrm{~W}$. In order 
to get a high extraction yield and save the time, $1 \mathrm{~h}$ was selected for the extraction of $S$. herbacea. Various ultrasonic powers $(15,45,75$ and $105 \mathrm{~W})$ were also investigated and the results showed ultrasonic power did not obvious affect the extracted yields of the organic acids. Thus, ultrasonic power of $75 \mathrm{~W}$ was considered for extraction.

Solid-phase extraction was utilized in order to isolate three organic acids from the $S$. herbacea extract. Extract sample was loaded onto amino imidazolium ionic liquids-based cartridge and then allowed to equilibrate for $6 \mathrm{~h}$. Washing and eluting steps were subsequently investigated to optimize the conditions. Initially, washing solvents with different polarities (water, methanol, acetonitrile, chloroform and $n$-hexane) were tested. Water was found to be the most suitable and then the volumes of washing water were optimized. The interferences could be eliminated by $3 \mathrm{~mL}$ of water with high recoveries of protocatechuic acid, caffeic acid and ferulic acid, respectively. And $1 \mathrm{~mL}$ of methanol was proved to be the best elution for three oranic acids from the amino imidazolium ionic liquidsbased cartridge (Fig. 3).

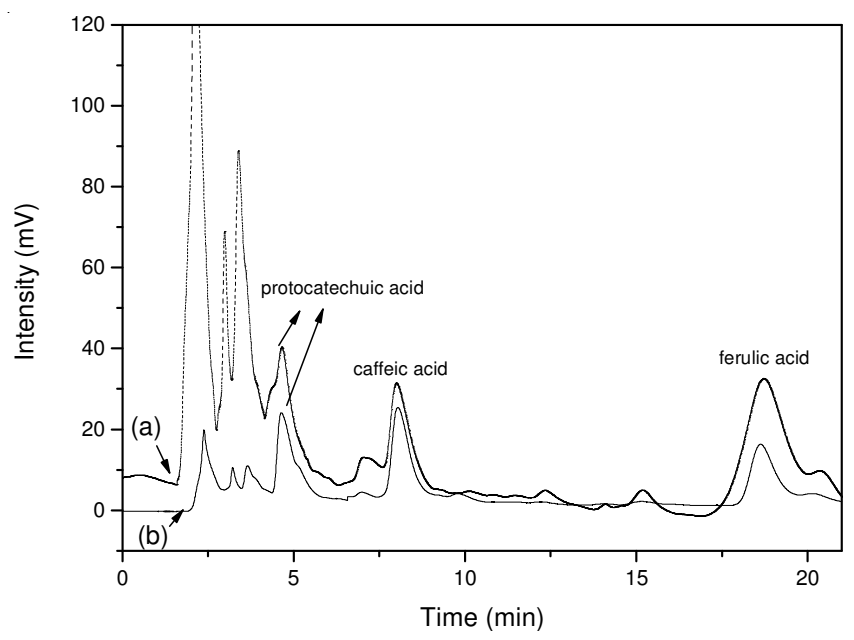

Fig. 3. Chromatogram of methanol extracts: (a) without SPE, (b) ionic liquids-based cartridge SPE extracts. (Mobile phase: acetonitrile/ $\mathrm{H}_{2} \mathrm{O} /$ acetic acid (15/85/0.05, v/v/v, $\left.\mathrm{pH} 5.0\right)$, flow rate: $0.8 \mathrm{~mL} \mathrm{~min}^{-1}$, column: $\mathrm{C}_{18}(5 \mathrm{~mm}, 150 \mathrm{~mm} \times 4.6 \mathrm{~mm}$, i.d. $), \mathrm{UV}: 270 \mathrm{~nm}$, injection volume: $10 \mathrm{~mL}$ )

Validation of the proposed method: Linearity of the method was tested at organic acid concentrations of 0.10-100 $\mu \mathrm{g} \mathrm{mL} \mathrm{L}^{-1}$ by measuring areas of the chromatographic peaks calibrated at five points over three repetitions. Three standard calibration curves were obtained $(\mathrm{Y}=27.87 \mathrm{X}-97.39, \mathrm{Y}=$ $23.42 \mathrm{X}-211.4$ and $\mathrm{Y}=15.40 \mathrm{X}-292.4$ ) by plotting the peak versus concentration and the determination coefficient $\left(\mathrm{r}^{2}\right)$ were 0.9999 for each equation, respectively. The sensitivity of the method was established through its limits of detection and limit of quantification (LOD and LOQ). Based on signal-tonoise ratios of 3 and 10, the LOD and LOQ were 0.04 and $0.10 \mu \mathrm{g} \mathrm{mL}^{-1}$ for three organic acids, respectively (Table-1).

Using quality control samples at three different concentrations $\left(10-100 \mu \mathrm{g} \mathrm{mL}^{-1}\right)$ of organic acid on intra- and interday, the accuracy and precision of the method were determined. The results showed that the intra-day relative standard deviations and inter-day relative standard deviations (RSDs) of the proposed method were less than 1.59 and $2.81 \%$, respectively. solidphase extraction recovery was calculated at the three concentration levels (low, medium and high) presented for assessing accuracy and precision and it was determined by comparing the measured concentration with the theoretical concentration. The recoveries of these three acids ranged from 79.6-85.2 \%, from $77.1-78.3 \%$ and from $76.5-85.5 \%$, respectively, which confirms the reliability of this method (Table-1).

Application of optimum condition for S. herbacea extracts: Three organic acids were extracted from $2 \mathrm{~g}$ S. herbacea powder under the optimum conditions. HPLC chromatograms of the methanol extracted samples with non-solid-phase extraction (Fig. 3a) and solid-phase extraction (Fig. 3b) were obtained. The results showed that the ionic liquid cartridge was effective for eliminating interfering peaks and this developed method had a high recovery of the analytes. Using this established method, the extract yield was $0.70,0.63$ and 0.52 $\mathrm{mg} \mathrm{g}^{-1}$ for protocatechuic acid, caffeic acid and ferulic acid, respectively.

\section{Conclusion}

The UAE of protocatechuic acid, caffeic acid and ferulic acid from $S$. herbacea was studied at various conditions. An amino imidazolium ionic liquids-based cartridge was prepared and developed for the selective extraction material. After washing with distilled water and eluting with methanol, three organic acids were successfully purified from the extract samples. The optimum extraction condition was obtained, extraction solvent of methanol, extraction time of $1 \mathrm{~h}$ and ultrasonic power of $75 \mathrm{~W}$. The HPLC analysis was operated with mobile phase of acetonitrile/ $\mathrm{H}_{2} \mathrm{O} / \mathrm{CH}_{3} \mathrm{COOH}(15 / 85 / 0.05$,

TABLE-1

INTRA-DAY AND INTER-DAY PRECISIONS, ACCURACIES AND RECOVERY OF THREE ORGANIC ACIDS FROM S. herbacea

\begin{tabular}{|c|c|c|c|c|c|c|c|c|}
\hline & \multirow{2}{*}{$\begin{array}{l}\text { Conc. } \\
\left(\mu \mathrm{g} \mathrm{mL}^{-1}\right)\end{array}$} & \multicolumn{3}{|c|}{ Intra-day } & \multicolumn{3}{|c|}{ Inter-day } & \multirow{2}{*}{$\begin{array}{c}\mathrm{SPE} \\
\text { recovery } \\
(\%)\end{array}$} \\
\hline & & $\begin{array}{l}\text { Measured conc. } \\
\left(\mu \mathrm{g} \mathrm{mL}{ }^{-1}\right)\end{array}$ & $\begin{array}{c}\text { Accuracy } \\
(\%)\end{array}$ & $\begin{array}{l}\text { Precision } \\
\text { RSD (\%) }\end{array}$ & $\begin{array}{l}\text { Measured conc. } \\
\qquad\left(\mu \mathrm{g} \mathrm{mL} \mathrm{mL}^{-1}\right)\end{array}$ & $\begin{array}{c}\text { Accuracy } \\
(\%)\end{array}$ & $\begin{array}{l}\text { Precision } \\
\text { RSD (\%) }\end{array}$ & \\
\hline \multirow{3}{*}{$\begin{array}{l}\text { Protocatechuic } \\
\text { acid }\end{array}$} & 10.00 & 10.04 & 100.40 & 0.40 & 10.19 & 101.84 & 1.80 & 80.2 \\
\hline & 50.00 & 49.63 & 99.27 & 0.74 & 49.99 & 99.98 & 0.02 & 79.6 \\
\hline & 100.00 & 99.82 & 99.82 & 0.18 & 100.43 & 100.43 & 0.43 & 85.2 \\
\hline \multirow{3}{*}{ Caffeic acid } & 10.00 & 10.16 & 101.61 & 1.59 & 10.29 & 102.89 & 2.81 & 77.1 \\
\hline & 50.00 & 49.25 & 98.50 & 1.52 & 50.15 & 100.30 & 0.30 & 89.3 \\
\hline & 100.00 & 99.19 & 99.19 & 0.82 & 100.72 & 100.72 & 0.72 & 78.3 \\
\hline \multirow{3}{*}{ Ferulic acid } & 20.00 & 20.07 & 100.35 & 0.35 & 19.92 & 99.60 & 0.40 & 80.1 \\
\hline & 50.00 & 50.01 & 100.03 & 0.03 & 49.04 & 98.08 & 1.96 & 76.5 \\
\hline & 100.00 & 100.81 & 100.81 & 0.80 & 97.37 & 97.37 & 2.71 & 85.5 \\
\hline
\end{tabular}


$\mathrm{v} / \mathrm{v} / \mathrm{v}, \mathrm{pH} 5.0$ ) and flow rate of $0.8 \mathrm{~mL} \mathrm{~min}^{-1}$, which showed good linearity for concentrations from $0.10-100.0 \mu \mathrm{g} \mathrm{mL}^{-1}$. Solid-phase extraction recoveries ranged from 76.5-89.3 with inter- and intra-day relative standard deviations less than $5 \%$. The extracted amounts were $0.70,0.63$ and $0.52 \mathrm{mg} \mathrm{g}^{-1}$ for protocatechuic acid, caffeic acid and ferulic acid, respectively.

Comparing with our previous work using molecular imprinted polymer as the extraction sorbent ${ }^{10}$, the solid-phase extraction recoveries and extraction yields of these three organic acids were increased in this purposed work. The results showed that the developed method exhibited high specificity and sensitivity, as well as the required precision, accuracy and recovery and its acceptability for drugs assay. The solid-phase extraction cartridge showed high affinity and selectivity to these organic acids and it was a promising material for separation of medicinal products from natural plants.

\section{ACKNOWLEDGEMENTS}

This research was supported by Basic Science Research Program through the National Research Foundation (NRF) of Korea funded by the Ministry of Education, Science and Technology (2012-0005250). This research was a part of the project titled "Korea Sea Grant Program (Gyeong-gi Sea Grant)" funded by the Ministry of Land, Transport and Maritime Affairs, Korea.

\section{REFERENCES}

1. Y.C. Jo, K.S. Lee, S.M. Chon and D.S. Byun, Korean J. Med. Crop Sci., 10, 100 (2002).

2. M.H. Rhee, H.J. Park and J.Y. Cho, J. Med. Plants Res., 3, 548 (2009).

3. J.G. Min, D.S. Lee, T.J. Kim, J.H. Park, T.Y. Cho and D.I. Park, Korean J. Food Sci. Nutri., 7, 105 (2002).

4. H.H. Lin, J.H. Chen, C.C. Huang and C.J. Wang, Int. J. Cancer, 120, 2306 (2007).

5. A. Saija, A. Tomaino, D. Trombetta, A.D. Pasquale, N. Uccella, T. Barbuzzi, D. Paolino and F. Bonina, Int. J. Pharm., 199, 39 (2000).

6. B.M. Jung, J.A. Park and S.J. Bae, J. Korean Soc. Food Sci. Nutr., 37, 148 (2008)

7. X. Chen, C. Yi, X. Yang and X. Wang, J. Chromatogr. B, 812, 149 (2004).

8. W. Bi, M. Tian, J. Zhou and K.H. Row, J. Chromatogr. B, 878, 2243 (2010).

9. A. Pukalskas, T.A. Beek and P. Waard, J. Chromatogr. A, 1074, 81 (2005).

10. T. Zhu, S. Li and K.H. Row, J. Appl. Polym. Sci., 121, 1691 (2011).

11. T. Zhu, W. Bi and K.H. Row, Chin. J. Chem., 29, 1759 (2011).

12. T. Zhu, W. Bi and K.H. Row, J. Appl. Polym. Sci., 118, 3425 (2010).

13. W. Gao, H. Yu and S. Zhou, J. Chromatogr. A, 71, 475 (2010).

14. M. Tian, H. Yan and K.H. Row, Anal. Lett., 43, 110 (2010).

15. Y. Yu, W. Zhang and S. Cao, Chin. J. Anal. Chem., 35, 1726 (2007).

16. E.D. Bates, R.D. Mayton, I. Ntai and J.H. Davis, J. Am. Chem. Soc., 124, 926 (2002).

17. W. Bi, T. Zhu, D.W. Park and K.H. Row, Asia-Pac. J. Chem. Eng., 7, 86 (2012). 